\title{
Research and Practice on Stereoscopic Teaching Resources Construction of the Computer Networks
}

\author{
Gao Fuxiang $^{1, \text { a }}$, Yao Lan ${ }^{1, \text { a }}$, Zhang Dongmei ${ }^{2, \mathrm{~b}}$ \\ ${ }^{1}$ College of Information Science and Engineering, Northeastern University, \\ Shenyang, 110819, China \\ ${ }^{2}$ College of Computer Science and Technology, Shandong University of Technology, \\ Zibo, 255049, China \\ aaemail:\{gaofuxiang, yaolan\}@mail.neu.edu.cn.com, bemail: zhang_dm@126.com
}

Keywords: Stereoscopic; teaching resource; networks; courseware

\begin{abstract}
With the development of reformation on teaching model of the computer networks course, construction of teaching resources is demanded more and more. It stares us in the face that teaching materials curricular or extracurricular; electronic or classic; on-line or off-line are needed to be set up. In this paper, the practice of stereoscopic teaching resources construction is concluded according to the authors' experiences. The architecture of stereoscopic teaching resources is proposed. Courseware development is exploited to illustrate rules which should be obeyed and right methods during the process of resources construction. This paper provides a helpful reference for resources construction of other similar courses.
\end{abstract}

\section{Introduction}

In the 21st century, in the development trend of science and technology that its core is informatization and digitalization, the new requirements are proposed for the study and popularity of computer network. The emergence and development of computer networks deeply affects people's production and life style of today's society. Computer network knowledge is must be mastered by each students of computer professionals[1-3]. And it reveals the knowledge of the architecture, composition principle, protocols, product standards, and the typical interconnect equipment work principle of all sizes networks from LAN, WAN to INTERNET. To master the computer networks is necessary for computer science students. "Computer network" is the important professional course for computer professionals. And it is also important course for similar professions, such as automation, electronic technology, communication engineering and so on. It is not only the lesson which learned before the "computer network technology", "network interconnection and Internet technology", and other courses, but also plays a important role in training to understand the network data transmission principle, the development and implementation of the protocol, network programming methods.

Through the learning of course, the students can understand the principles of computer network communication, and master the details of the agreement of all levels of the network architecture. And on this basis, the students can understand the operating principle of a variety of network interconnect devices and understand how to use them. According to the principle the students also can solve the problems in the network, and do network development. Theses are the unique expertise of computer science students.

In the traditional teaching mode, the teacher is in active position of learning activities, students is passive taught. With the deepening of teaching reform and the change of student characteristics in recent years, active learning and research study appear and occupy an increasingly important position in the teaching activities gradually. Classroom teaching alone can no longer meet the needs of the teaching activities, and therefore that construct a stereoscopic teaching resources to support the new teaching model reform and multi-form autonomous learning is required.

Starting from the experience of teaching undergraduate computer network courses for many 
years, and on the basis of in the summary and study, the paper proposed architecture to build a stereoscopic teaching resources, and to explore key issues and practical method of making multimedia courseware. Finally, a summary is given.

\section{The Architecture of the Stereoscopic Teaching Resources}

The computer network course explains the principle of computer networks to students in hierarchical method, and focused on the protocols principle and the key technology in each layer, to enable students to build a computer network architecture concept.

The difficulty of course is that computer network protocols are "soft" concept, it is abstract and difficult to understand for students. But students often contact the real computer network. They have been intuitive understanding for network, and they can use the network. With this feature, in the process of teaching, the practical application examples are combined with the principle, and the experiments related with the teaching content are arranged, so that students have the impression after listening, can understand well. The students can master Principles and Techniques well also after the experiments. Such students do more the experiments, combined with the day-to-day actual application. So, the good teaching results have achieved.. This also requires that we not only provide static teaching resources, dynamic, and multimedia teaching resources that are more conducive to students understood.

The book "Computer networks" written by Professor Xie Xiren (second edition, third edition, fourth edition, fifth edition) has been selected as text book of computer network course since 2002. This book is national planning textbook in the "11th Five-Year Plan", and was selected as textbook of computer network course by many universities.

In development of teaching content, based on the book written by Xie, our teaching group have down the necessary adjustments, and made the electronic teaching plans and courseware. These teaching resources played a significant role in the teaching. Ended the second half of 2012, the electronic teaching resources in the course server have been download up to 3100 times.

We designed practice teaching activities closely around the classroom teaching content of computer network. Using advanced laboratory equipment and resources, through experimental procedures, the students can well understand related concepts, principles, techniques, and master some methods of the network equipment operation.

Before Practical Teaching Reform in 2005, computer network course experiments are only read of RFC documents, simple use of practical server operating command. The students are not interested in teaching. The teaching results also poor. Therefore, the university has invested a lot of money and manpower, and made experimental reforms. From the experiment contents and means to more aspects of the technology, etc., the level of the computer network experiment is greatly improved.

Due to the change of the network environment of the university, in the bedroom, almost every day, the students can come into contact with a computer network; they already have a network application infrastructure. For example, some students purchased the cable and routing equipment, built a small LAN. LAN can run, but which contains three questions: (a) standard network cable, why this standard; (2) principle of the routing equipment and the use of large routing equipment; (3) whether there are other types of LAN, what their standard. The answers to these questions will be found in the classroom. Building in the practice teaching resources, with the content of classroom teaching, practical classes scheduled cable made, local area network design, router configuration and so on. In this reform, the teaching group written tutorial of the electronic version of the experiment. Closely integrated with the teaching content, we have set up 16 experimental projects. Experimental contents from easy to complex, contains both basic experiment, also includes exploratory experiment, in full compliance with the law of student learning. Experimental teachers provide students with a detailed video experimental guidance information, text guidance information and examples. Students in accordance with the guidance information can successfully complete experiments. After arrangement of experiments, the instructor login the QQ and Forum, and guidance to students with real-time and non-real-time. The experiment of computer network has 
become a leader in the national universities in similar experimental lesson.

Through the practice teaching, the students will master the basic theory, methods, techniques and practical application, deeply understand the principle of the computer network, and learn the practical skills that can not be learned in the classroom.

Practice teaching experience of several years show that through the practical learning, students can master the LAN network construction; the use of subnet mask, and the IP address; simple Socket programming; able to complete the operation of the network equipment. The theory of classroom teaching has been proven to stimulate students' interest in learning.

In addition, for the students who did not keep up with the progress of teaching or would like to recall the content of classroom teaching, we provide online guidance, electronic lesson plans and teaching video, which contains a lot of animation, video , charts, etc., so that students can continue learning classroom knowledge through the network.

Learning resources like Q\&A and Forum are the strong guarantee to reinforce learning. Collective Q\&A activities are generally arranged three per semester, the middle of the course, before the end of the course and exam. For the students who need individual Q\&A, the Q\&A can be completed at any time by the teacher Email. The forum is a more flexible form, the students can leave a message at any time, teacher can login at least once each day, can discuss problems with students on the forum.

In order to evaluate the effect of student learning, in learning resources, we have established a comprehensive evaluation system combined in a variety of forms of learning evaluation, including online self-test, and regularly small test, lab reports, final exam.

The questions types of self-test questions include fill-in-the-blank, select. They are objective questions covering the basic content of the corresponding sections of the requirements, especially where students prone to error. We provide self-test exercises on the web site. After students self-test, the system will automatically mark, and give the standard answer. According to the answer situation, students can determine the effect of learning in this chapter. If in doubt, students can discuss with teachers in a variety of ways.

The course study resources architecture is shown in Figure 1.

\begin{tabular}{|c|c|c|c|c|c|c|c|}
\hline Online Q\&A & \multicolumn{2}{|c|}{ Online download } & test & \multicolumn{2}{|c|}{ Video on demand } & Printout & CD \\
\hline $\begin{array}{l}\text { Records of } \\
\text { Q\&A, } \\
\text { records of } \\
\text { homework, } \\
\text { discussions } \\
\text { record }\end{array}$ & $\begin{array}{l}\text { Electronic } \\
\text { courseware }\end{array}$ & $\begin{array}{l}\text { Electronic } \\
\text { textbook and } \\
\text { experimental book }\end{array}$ & $\begin{array}{l}\text { Exam } \\
\text { library } \\
\text { and } \\
\text { simulation } \\
\text { questions }\end{array}$ & $\begin{array}{l}\text { Videos } \\
\text { of } \\
\text { lectures }\end{array}$ & $\begin{array}{l}\text { Multimedia } \\
\text { materials }\end{array}$ & $\begin{array}{l}\text { Textbook } \\
\text { and } \\
\text { experiment } \\
\text { book }\end{array}$ & $\begin{array}{l}\text { Problem } \\
\text { sets and } \\
\text { simulation } \\
\text { test } \\
\text { questions }\end{array}$ \\
\hline \multicolumn{6}{|c|}{ Online learning materials } & \multicolumn{2}{|c|}{$\begin{array}{c}\text { Offline learning } \\
\text { materials }\end{array}$} \\
\hline
\end{tabular}

Fig. 1. Course learning resource architecture

By the establishment of the architecture of the course learning resources, we establish Stereoscopic teaching resources, and provide strong support for inquiry learning for students.

\section{Multimedia Courseware Production Practice}

Multimedia courseware is a kind of course software that teachers produce teaching content in multimedia format in accordance with the teaching plans and course requirements.

The multimedia courseware of computer network courses should follow the following principles:

-Visualization.

- easy to understand.

- clear and concise.

Courseware should be a summary of teaching experience, secondary summarized and 
explained[4]. But in the actual teaching, due to insufficient summarized some teachers simple copy from the textbook; Some teachers do not pay attention to the rhythm of teaching, classroom blank insufficient excess content; Some teachers focus too much on the technical content of the courseware, and led to putting the cart before the horse, so that students feel dazzling.

Therefore, our course group made courseware production standards in reference to the reference [5], as shown in Table 1.

Tab. 1. multimedia courseware specification

\begin{tabular}{|c|c|c|}
\hline \multirow{4}{*}{ Scientific } & Concept & Scientific, accurate, standardized \\
\hline & Problem statement & Accurate \\
\hline & Citation & Accuracy, format specification \\
\hline & Logic & Comply with the law \\
\hline \multirow{4}{*}{ Instructive } & Intuitive & Intuitive and image \\
\hline & Novelty & Innovative \\
\hline & Enlightening & Left the room to the students to think about and interactive \\
\hline & Targeted & Targeted, content integrity \\
\hline \multirow{4}{*}{ Technical } & Stability & Courseware stable operation, no error \\
\hline & Maintainability & Conducive to upgrade and improve \\
\hline & Rationality & Development based on general software \\
\hline & Portability & Can run in a different configuration computer \\
\hline \multirow{3}{*}{ Artistic } & Picture composition & Certain artistic, practical and clear \\
\hline & Writing & A simple, text-specification \\
\hline & Sound, animation and other effects & Clear \\
\hline
\end{tabular}

\section{Conclusion}

After building stereoscopic teaching resources, we can provide students with a variety of offline, online expansion of materials. We provide online learning help. When students encounter problems in the study, the problem can be resolved in time. The construction of this kind of teaching resources will help to promote the reform of the teaching mode, provide a strong guarantee for the innovation of the way students learn.

\section{References}

[1] Jiang Weixing. Teaching Research on Computer Network Curriculum[J], Computer knowledge and Technology, 2008, 4(3): 682-683.

[2] Xie Xiren. Computer Networks(5 ${ }^{\text {rd }}$ ed.)[M], Beijing: Publishing House of Electronics Industry, 2007.

[3] Wu Yigong. Computer Networks( $2^{\text {nd }}$ ed.)[M], Beijing: Tsinghua University Press, 2006.

[4] Li Xiaolei. Preliminary Discussion of Universities Computer Network Courseware[J], Science \& Technology Information, 2009, (14): 569-570.

[5] The multimedia courseware evaluation criteria (Trial) of Zhongnan University Economic and Law[EB/OL], http://gsxy.znufe.edu.cn/Article/2008-8/200883091555855.html, 2008. 